\title{
Econometric Analysis of Malnutrition Severity Among Under Five Children in Bangladesh
}

Khnd. Md. Mostafa Kamal ${ }^{{ }^{*}}$ and Naimul Islam ${ }^{2}$

${ }^{1}$ Department of Statistics, Biostatistics and Informatics , Dhaka University, Dhaka-1000, Bangladesh

${ }^{2}$ Essential Health Care; Health, Nutrition and Population program, BRAC, Dhaka, Bangladesh

(Received: 7 April 2012; Accepted: 22 August 2013)

\begin{abstract}
The nutritional status of under-five children is one of the sensitive indicators of a country's health status. This study investigated differential impact of some demographic, socioeconomic and health related factors on nutritional status among under-five children in Bangladesh based on Bangladesh Demographic and Health Survey 2007 (BDHS 2007) data. The main contributing factors of malnutrition among under-five children is linked to the family's economic condition, parent's education, sources of drinking water, type of toilet facility, child's birth interval, child's birth order, mass media exposure, having diarrhoea or Acute Respiratory Infections (ARI) recently, housing condition and place of residence. An ordered probit analysis of the effects of selected socioeconomic and demographic factors on malnutrition indicates that the strongest predictors of nutritional status of children in Bangladesh are gender of child, parent's education, family's economic condition and household standard of living.
\end{abstract}

Key words: Stunting (height for age), wasting (weight for height) underweight (weight for age), under five children, Ordered probit.

\section{Introduction}

Malnutrition is the condition that results from taking an unbalanced diet in which certain nutrients are lacking, in excess (too high an intake), or in the wrong proportions. Approximately half of the 10.4 million children of our country who die each year are malnourished. The World Health Organization (WHO) cites malnutrition as the greatest single threat to the world's public health. A number of different nutritional disorders may arise, depending on which nutrients are under or over abundant in the diet. According to the United Nations Reports on the Right to Food for 2000 to March 2008, mortality due to malnutrition accounted for $58 \%$ of the total mortality in 2006: In the world, approximately 62 million people, all causes of death combined, die each year. One in twelve people worldwide is malnourished. In 2006, more than 36 million died of hunger or diseases due to deficiencies in micronutrients.

Kabirullah et $\mathrm{al}^{1}$ showed that $14 \%$ of the children aged under 4 months had normal body weight which decreases to about $5 \%$ at the age of 5 years. Among them $31 \%$ of the children suffered from third degree malnutrition and they grew up as shorter and thinner. They also found that with the increase of age, the weight-for-age and weight-forheight decreased. Bairagi and Chowdhury ${ }^{2}$ investigate that the importance of family income in relation to some other socio demographic factors, that might affect the nutritional status of children in rural Bangladesh. He observed that the seasonal factors, family income, mother's education sex and birth order of children are the important determinant of malnutrition. Haque et $\mathrm{al}^{3}{ }^{3}$ showed that programs on nutritional awareness aired through mass media had influence on the level of awareness of the respondents. Mozumder et al. ${ }^{4}$ showed that children in families with short subsequent birth intervals are significantly more likely to be moderate-to-severely or severely malnourished than those children in families having longer intervals before the birth of another child in the family. A number of variables related to infant and child malnutrition including low dietary intake, low birth weight, family size, lack of parental education, faulty infant feeding practices, incidence of diarrhoea and delayed weaning. ${ }^{5,6,8}$ Inadequate nutrition of the mother may also be responsible for malnutrition in breast-fed infants and young children. ${ }^{9}$ Rahman and Chowdhury ${ }^{10}$ and Chaudhuri ${ }^{11}$ showed that the MCH program, is statistically significant for long-term health (measured in height-for-age) as well as short-term health (measured in weight-for-age), but not on acute growth disturbances (measured in weightfor-height). Furthermore, a probit model estimation was performed by using a discrete dependent variable indicating stunting (low height-for-age), wasting (low weight-forheight) and being underweight (low weight-for-age) among children to capture the program effect on extreme health outcomes. Isanaka S, Villamor E, Shepherd S, Grais RF of $\mathrm{WHO}^{12}$ revealed how program enrollment and infant health outcomes would have changed if the 2006 World Health Organization growth standards had been used to identify severely malnourished children in a Médecins Sans Frontières feeding program like Niger.

The prevalence of malnutrition in Bangladesh is amongst the highest in the world. Millions of children suffer from one or more forms of malnutrition, including: low birth weight, stunting, underweight, vitamin A deficiency, iodine deficiency disorders and anemia. From the above discussion it is clear that there is no place for negligence of the severity issue of child malnutrition in Bangladesh. But almost all the previous studies are based on bivariate and logistic approach. Through this study the current state and prevalence of child malnutrition in Bangladesh was analyzed by using ordered probit approach. The main objective of the study is to understand \& identify the factors affecting the severity of malnutrition in Bangladesh. For this purpose, three types of malnutrition severity analyses have been incorporated, such as: Underweight, Stunting \& Wasting. Independent variables are categorized into Child Characteristics, Household Characteristics, Socioeconomic Characteristics and Mother's Autonomy. In order to reach the objective, data from Bangladesh Demographic and Health Survey (BDHS) ${ }^{13}$ has been used.

*Author for Correspondence.e-mail: mostafastat@yahoo.com 


\section{Methodology}

Ordered Probit Model: Though multinomial Logit (MNL) model is the most widely used model due to its simple mathematical structure and easy to estimate, it imposes a restriction random error terms since the dependent variable is of ordinal in nature. Also Multinomial and nested Logit model cannot handle ordinal dependent variable. Consequently, there will be loss of efficiency due to information being ignored. One way to deal with this problem is to use ordered probit model instead of multinomial Logit and nested Logit model. The ordered probit model discerns unequal differences between ordinal categories in the dependent variable. ${ }^{14,15}$ The general form of the model, $y_{i}^{*}=x_{i} \beta+\varepsilon_{i}$ Where, $y_{i}^{*}$ is a row vector of observed non-random explanatory variables; $\beta$ is a vector of unknown parameter; is the random error term; which is assumed to be normally distributed. According to Long, ${ }^{16}$ the ordered probit model can be derived from a measurement model in which a latent variable $y_{i}^{*}$ ranging from $-\infty$ to $+\infty$ is mapped to an observed ordinal variable $y$. The observed and coded discrete variable is determined from $y_{i}=m$, if $\tau_{m-1} \leq y^{*}<\tau_{m}$ from $\mathrm{m}=1$ to $\mathrm{M}$, where the threshold values $\tau$ 's are unknown parameters to be estimated. The extreme categories, 1 and $\mathrm{M}$, are defined by open-ended intervals with $-\infty$ and $=+\infty$. The mapping from the latent variable to the observed categories is illustrated in Figure below:

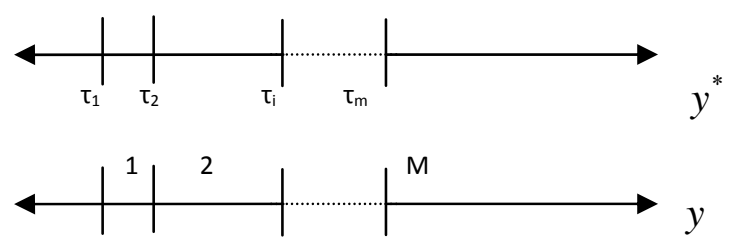

Fig.1. Mapping of latent variable to observed variable

However, O'Donnell and Connor ${ }^{17}$, Kockelman et al. ${ }^{18}$ have recognized that the discrete measure of severity is ordinal in nature and have applied the ordered probit or ordered logit models to severity studies. The difference between the two models lies in the assumption of errors. They have further indicated that the results from the ordered probit and ordered Logit are similar. However, ordered probit model is preferable because the assumption that the distribution of errors is normally distributed is more likely to be valid.

Since severity of malnutrition is necessarily ordered (mild, moderate \& severe), ordered probit model is appropriate for malnutrition severity studies; therefore it has been chosen for our study. This model requires no assumptions regarding the ordinarily of the dependent variable, i.e., severity score. Further, ordered probit model can account for more than two states of severity of malnutrition which Logit and probit model cannot do. It can account for both the categorical and the ordinal nature of dependent variable (severity of malnutrition). In addition, ordered probit model is not associated with undesirable properties such as lack of a closed form that likely to be found in multinomial Logit model and multinomial probit model. When the expected value of severity is interpreted as probability in ordered probit model, the ranges could not be outside between 0 and 1 like multiple linear regression model.

Z - Score or Standard Deviation System: Height and weight are compared with the NCHS reference standard and are expressed as percentage deviations or as standard deviation scores ( $Z$ scores) of the reference medians. The distributions of height-for-age and weight-for-age $Z$ scores are very close to standardized Gaussian (Normal) distribution because the population has a normal distribution with mean of 0 and standard deviation of 1.The mathematical expressions is $\mathrm{Z}$ $=\frac{\text { Observed value }- \text { Median }}{\text { Standard deviation }}$. According to WHO the used Zscores are :

\begin{tabular}{|l|l|l|}
\hline Z-score & Malnutrition & Code \\
\hline Z-scores $\geq$-2SD & Mild & 1 \\
\hline -2SD $>$ Z-scores $\geq$-3SD & Moderate & 2 \\
\hline -3SD $>$ Z-scores & Severe & 3 \\
\hline
\end{tabular}

\section{Result and Discussion}

Bivariate analysis: It was revealed from BDHS 2007 that, among the 4,125 children, $40 \%, 19 \%$ and $40 \%$ were underweight, wasting and stunt respectively (according to 5 modules designed by the WHO in 2008). From the data, $14.8 \%, 3.2 \% \& 15 \%$ of the cases were classified as severe malnutrition in terms of underweight, wasting and stunt respectively and $25.1 \%, \quad 16 \% \quad \& 24.2 \%$ as moderate malnutrition respectively.

Model Evaluation: To confirm suitability of the fitted model, the goodness of fit index has been used. Although these values seemed low in our study, they are comparable with those in other malnutrition severity studies where ordered probit model was employed. ${ }^{14,15,16,18}$ The following model result is justified to explain variations in malnutrition severity.

Table 1. Goodness of Fit Statistics

\begin{tabular}{|c|c|c|c|c|c|c|}
\hline $\begin{array}{l}\text { Thres } \\
\text { hold }\end{array}$ & Weight for Age, (Height fo & $\begin{array}{l}\text { Weight } \\
\text { height\} }\end{array}$ & \multicolumn{2}{|c|}{$\begin{array}{l}\text { Goodness of } \\
\text { Fit }\end{array}$} & \multicolumn{2}{|l|}{ Log Likelihood } \\
\hline$\tau_{1}$ & $(4.9)$ & $\{0.3\}$ & $p^{2}$ & .186 & $\begin{array}{l}\text { Intercept (-2 log } \\
\text { likelihood) }\end{array}$ & 7590 \\
\hline$\tau_{2}$ & $(4.1)$ & $\{0.9\}$ & $\bar{\rho}^{-1}$ & .157 & $\begin{array}{l}\text { Final (-2 log } \\
\text { likelihood) }\end{array}$ & 6888 \\
\hline \multicolumn{3}{|c|}{ Number of observation } & \multicolumn{4}{|l|}{4125} \\
\hline
\end{tabular}


Child Characteristics: The negative coefficients (-.573, $.41,-.3)$ indicate that severity of malnutrition is smaller in male children compared with female child. The relative severe underweight malnutrition probability of male child is 0.53 . Table 1 also show that a higher risk of severity is associated with not received BCG vaccination. The severe underweight malnutrition risk is $39 \%$ higher than reference group (i.e. who received BCG vaccination) and the percentage is increased for stunting \& wasting. The result shows that a higher severity risk is associated with the children with diarrhoea where the chance of a severe underweight malnutrition is $24 \%$ smaller for the children who had not. For stunting \& wasting, the percentage is $21 \%$ $\& 13 \%$ smaller respectively. Here the estimated value of the coefficient of current age of child is .081 i.e. $8 \%$ average increase in underweight malnutrition when child age increases by one month. Similarly, the percentage is increased for stunting \& wasting. The results also show that a higher underweight malnutrition severity risk is associated with 3rd \& 4th birth order. It may happen from the fact that the first baby of any family gets some extra facilities than the other babies of the family (Chaudhuri A.2004).

Table 2. Order Probit Model Analysis Results( Child Characteristics)

\begin{tabular}{|c|c|c|c|c|c|c|c|c|c|c|c|c|}
\hline & $\begin{array}{l}\text { Weight } \\
\text { for Age }\end{array}$ & $\begin{array}{l}\text { Height } \\
\text { for Age }\end{array}$ & $\begin{array}{l}\text { Weight for } \\
\text { Height }\end{array}$ & \multicolumn{3}{|c|}{ Weight for Age } & \multicolumn{3}{|c|}{ Height for Age } & \multicolumn{3}{|c|}{ Weight for Height } \\
\hline \multicolumn{4}{|c|}{ Coefficients } & \multicolumn{3}{|c|}{$\begin{array}{l}\text { Ratio relative } \\
\text { to ref. case }\end{array}$} & \multicolumn{3}{|c|}{$\begin{array}{l}\text { Ratio relative } \\
\text { to ref. case }\end{array}$} & \multicolumn{3}{|c|}{$\begin{array}{l}\text { Ratio relative } \\
\text { to ref. case }\end{array}$} \\
\hline $\begin{array}{l}\text { Sex of child } \\
\text { female }=1\end{array}$ & & & & Mild & Moderate & Severe & Mild & $\begin{array}{l}\text { Moderat } \\
e\end{array}$ & Severe & Mild & $\begin{array}{l}\text { Moderat } \\
e\end{array}$ & Severe \\
\hline male $=2$ & $-.573 * *$ & $-.41 * *$ & $-.306 * *$ & 0.69 & 0.625 & 0.534 & 1.21 & 0.738 & 0.58 & 1.16 & 0.615 & 0.757 \\
\hline Current age of child & $.081 * *$ & $0109 * *$ & $-.108 * *$ & & & & & & & & & \\
\hline \multicolumn{13}{|c|}{ Birth order number ( Birth order $1=1$ ) } \\
\hline Birth order $2=2$ & $-.101 *$ & -.034 & -.075 & 0.986 & 1.095 & 0.928 & 0.966 & 1.087 & 1.041 & 1.011 & 1.020 & 0.917 \\
\hline Birth order $3=3$ & $.173 *$ & -.023 & $-.156^{*}$ & 0.984 & 1.173 & 0.817 & 0.931 & 1.160 & 1.114 & 1.025 & 1.106 & 0.737 \\
\hline Birth order $4=4$ & .035 & .059 & -.042 & 0.792 & 1.505 & 1.124 & 0.812 & 1.403 & 1.358 & 0.975 & 1.119 & 1.008 \\
\hline Birth order $\geq 5=5$ & -.061 & .134 & -.131 & 0.850 & 1.114 & 1.458 & 0.768 & 1.209 & 1.911 & 1.008 & 0.874 & 1.098 \\
\hline \multicolumn{13}{|c|}{ Currently breast feeding $(\mathrm{No}=1)$} \\
\hline Yes $=0$ & .452 & -.297 & $0-.566$ & 0.947 & 0.988 & 1.261 & 0.965 & 1.126 & 0.960 & 1.215 & 0.561 & 0.547 \\
\hline \multicolumn{13}{|c|}{ Received BCG ( Yes=1) } \\
\hline $\mathrm{No}=0$ & $.297 * *$ & $.177^{*}$ & $.406 * *$ & 0.752 & 1.373 & 1.386 & 0.885 & 1.087 & 1.364 & 0.707 & 1.164 & 2.696 \\
\hline \multicolumn{13}{|c|}{ Received DPT 3( Yes=1) } \\
\hline $\mathrm{No}=0$ & -.041 & -.019 & -.012 & 0.925 & 1.099 & 1.137 & 1.000 & 0.923 & 1.118 & 0.823 & 1.147 & 2.038 \\
\hline \multicolumn{13}{|c|}{ Received POLIO 3 ( Yes=1) } \\
\hline $\mathrm{No}=0$ & .079 & .125 & .177 & 0.932 & 1.107 & 1.104 & 1.003 & 0.944 & 1.076 & 0.816 & 1.209 & 1.991 \\
\hline \multicolumn{13}{|c|}{ Received MEASLES (Yes=1) } \\
\hline $\mathrm{No}=0$ & -.103 & $-.273 * *$ & -.069 & 1.010 & 0.921 & 1.085 & 1.110 & 0.775 & 0.933 & 0.864 & 1.143 & 1.820 \\
\hline \multicolumn{13}{|c|}{ Had diarrhea recently $(\mathrm{Yes}=1)$} \\
\hline $\mathrm{No}=0$ & $-.181 * *$ & $-.154 *$ & -.076 & 1.132 & 0.911 & 0.764 & 1.087 & 0.943 & 0.799 & 1.058 & 0.802 & 0.877 \\
\hline
\end{tabular}

**significant at $1 \%$ level $\quad *$ significance at $5 \%$ level

Household Characteristics: The results in Table2 show that, a higher child malnutrition severity risk is associated with the reference group (i.e. Sylhet). The relative severe malnutrition probabilities of Khulna is 0.64 indicating that the chance of a severe malnutrition is $36 \%$ smaller than Sylhet and the relative severe malnutrition probabilities of Khulna is smaller than other division. Similarly, the negative coefficient indicates; Chittagong, Dhaka, Khulna and Rajshahi have smaller risk of underweight malnutrition severity than Sylhet. Table 2 also shows that the risk of moderate \& severe underweight malnutrition is smaller for primary education group, secondary education group and higher education group compared with the No education. 
Table 3. Order Probit Model Analysis Results (Household Characteristics)

\begin{tabular}{|c|c|c|c|c|c|c|c|c|c|c|c|c|}
\hline & $\begin{array}{l}\text { Weight for } \\
\text { Age }\end{array}$ & $\begin{array}{l}\text { Height for } \\
\text { Age }\end{array}$ & $\begin{array}{l}\text { Weight for } \\
\text { Height }\end{array}$ & \multicolumn{3}{|c|}{ Weight for Age } & \multicolumn{3}{|c|}{ Height for Age } & \multicolumn{3}{|c|}{ Weight for Height } \\
\hline \multicolumn{4}{|c|}{ Coefficients } & \multicolumn{3}{|c|}{$\begin{array}{l}\text { Ratio relative } \\
\text { to ref. case }\end{array}$} & \multicolumn{3}{|c|}{$\begin{array}{l}\text { Ratio relative } \\
\text { to ref. case }\end{array}$} & \multicolumn{3}{|c|}{$\begin{array}{l}\text { Ratio relative } \\
\text { to ref. case }\end{array}$} \\
\hline \multicolumn{4}{|c|}{ Type of place of residence $(1=$ Rural $)$} & Mild & $\begin{array}{l}\text { Moderat } \\
\mathrm{e}\end{array}$ & Severe & Mild & $\begin{array}{l}\text { Moderat } \\
\mathrm{e}\end{array}$ & Severe & Mild & Moderate & Severe \\
\hline $2=$ Urban & .017 & .036 & -.032 & 1.188 & 0.794 & 0.714 & 1.154 & 0.803 & 0.735 & 1.084 & 0.840 & 0.761 \\
\hline \multicolumn{13}{|l|}{ Division (1 = Sylhet $)$} \\
\hline $2=$ Chittagong & -.102 & .081 & -.029 & 0.996 & 1.033 & 0.968 & 1.007 & 1.032 & 0.941 & 1.039 & 1.013 & 0.834 \\
\hline $3=$ Dhaka & -.045 & -.087 & $-.137 *$ & 1.072 & 0.988 & 0.798 & 1.050 & 1.079 & 0.750 & 1.109 & 0.868 & 0.692 \\
\hline $4=$ Khulna & $-.174 *$ & $-.221 * *$ & -.154 & 1.198 & 0.817 & 0.638 & 1.166 & 1.023 & 0.447 & 1.122 & 0.906 & 0.604 \\
\hline $5=$ Rajshahi & $-.142 *$ & $-.193 * *$ & $-.222 * *$ & 1.062 & 1.130 & 0.644 & 1.108 & 1.144 & 0.574 & 1.104 & 1.00 & 0.580 \\
\hline $6=$ Barisal & -.026 & .036 & -.089 & 1.004 & 1.041 & 0.936 & 0.970 & 1.157 & 0.920 & 1.057 & 1.038 & 0.746 \\
\hline \multicolumn{13}{|c|}{ Father's education level ( $0=$ "No education") } \\
\hline $1=$ "Primary" & $-.051 *$ & -.041 & -.07 & 1.057 & 1.007 & 0.842 & 1.068 & 0.996 & 0.832 & 1.038 & 0.916 & 0.915 \\
\hline 3 = "Higher" & $-.213 *$ & $-.371 * *$ & -.036 & 1.508 & 0.489 & 0.391 & 1.532 & 0.509 & 0.248 & 1.147 & 0.705 & 0.624 \\
\hline \multicolumn{13}{|c|}{ Father's occupation (1 = "Unemployed") } \\
\hline 2 = "agricultural sector" & .182 & .275 & .185 & 0.850 & 2.091 & 1.822 & 0.728 & 1.627 & 2.157 & 0.880 & 1.551 & 1.327 \\
\hline $\begin{array}{l}3=\text { "Business \& } \\
\text { professional " }\end{array}$ & -.072 & .162 & .184 & 1.151 & 1.357 & 1.131 & 0.940 & 1.211 & 1.124 & 0.959 & 1.290 & 1.00 \\
\hline 4 = "worker" & .089 & .221 & .160 & 0.985 & 1.790 & 1.486 & 0.809 & 1.491 & 1.719 & 0.908 & 1.495 & 1.178 \\
\hline $5=$ "others" & .153 & .089 & .238 & 1.012 & 1.434 & 1.804 & 0.893 & 1.273 & 1.404 & 0.767 & 1.766 & 1.916 \\
\hline Father's age & -.007 & $-.010^{*}$ & $-.007 * *$ & & & & & & & & & \\
\hline \multicolumn{13}{|c|}{ Religion $(1=$ other religion $)$} \\
\hline 2 = Islam & -.055 & .019 & -.082 & 1.03 & 0.928 & 1.006 & 0.992 & 1.013 & 1.014 & 1.030 & 1.00 & 0.855 \\
\hline
\end{tabular}

$* *$ significant at $1 \%$ level * significance at $5 \%$ level

Economic Characteristics: The results in Table 3 show that, underweight child malnutrition severity is smaller for flush toilet \& pit toilet over the other facilities of toilet in the house of child. The chance of severe malnutrition of the flush toilet users is $47 \%$ smaller than the reference category. The results in Table 3 also show that malnutrition severity of children is smaller for having electricity.

Table 4. Order Probit Model Analysis Results (Economic Characteristics)

\begin{tabular}{|c|c|c|c|c|c|c|c|c|c|c|c|c|}
\hline & $\begin{array}{l}\text { Weight } \\
\text { for Age }\end{array}$ & $\begin{array}{l}\text { Height } \\
\text { for Age }\end{array}$ & $\begin{array}{l}\text { Weight } \\
\text { for Height }\end{array}$ & \multicolumn{3}{|c|}{ Weight for Age } & \multicolumn{3}{|c|}{ Height for Age } & \multicolumn{3}{|c|}{ Weight for Height } \\
\hline \multicolumn{4}{|c|}{ Coefficients } & \multicolumn{3}{|c|}{$\begin{array}{l}\text { Ratio relative } \\
\text { to ref. case }\end{array}$} & \multicolumn{3}{|c|}{$\begin{array}{l}\text { Ratio relative } \\
\text { to ref. case }\end{array}$} & \multicolumn{3}{|c|}{$\begin{array}{l}\text { Ratio relative } \\
\text { to ref. case }\end{array}$} \\
\hline \multicolumn{4}{|c|}{ Source of drinking water $(0=$ other $)$} & Mild & $\begin{array}{l}\text { Moderat } \\
\mathrm{e}\end{array}$ & Severe & Mild & $\begin{array}{l}\text { Modera } \\
\text { te }\end{array}$ & Severe & Mild & $\begin{array}{l}\text { Moderat } \\
\mathrm{e}\end{array}$ & Severe \\
\hline 1 = "tube well" & .073 & .093 & .05 & 1.024 & 1.020 & 0.887 & 0.943 & 1.194 & 0.987 & 1.068 & 0.870 & 0.840 \\
\hline 2 = "piped water" & .134 & .0186 & -.096 & 1.215 & 0.730 & 0.672 & 1.090 & 0.915 & 0.728 & 1.206 & 0.599 & 0.540 \\
\hline \multicolumn{13}{|c|}{ Type of toilet facility $(0=$ other $)$} \\
\hline $1=$ Flush Toilet & $-.173^{*}$ & $-.17^{*}$ & $-.04 *$ & 1.369 & 0.649 & 0.538 & 1.295 & 0.815 & 0.417 & 1.154 & 0.639 & 0.741 \\
\hline $2=$ Pit Toilet & -.088 & $-.13 * *$ & .07 & 1.112 & 0.916 & 0.827 & 1.088 & 1.042 & 0.714 & 1.050 & 0.863 & 0.942 \\
\hline \multicolumn{13}{|c|}{ Has electricity $(0=$ No $)$} \\
\hline $1=$ Yes & $-.012 *$ & .024 & -.036 & 0.823 & 1.243 & 1.504 & 0.810 & 1.196 & 1.881 & 0.923 & 1.286 & 1.168 \\
\hline \multicolumn{13}{|c|}{ Reading newspaper or magazine $(0=$ No $)$} \\
\hline $1=$ Yes & $-.023 *$ & .03 & .104 & 0.777 & 1.529 & 1.742 & 0.722 & 1.503 & 2.091 & 0.912 & 1.40 & 1.204 \\
\hline \multicolumn{13}{|c|}{ Frequency of listening to $\operatorname{radio}(0=\mathrm{No})$} \\
\hline $1=$ Yes & $.117^{*}$ & .03 & -.093 & 1.040 & 0.889 & 1.053 & 0.973 & 0.934 & 1.281 & 1.034 & 0.938 & 0.904 \\
\hline \multicolumn{13}{|c|}{ Frequency of watching television $(0=$ No $)$} \\
\hline $1=$ Yes & $-.023 *$ & .233 & -.005 & 0.863 & 1.174 & 1.346 & 0.843 & 1.158 & 1.50 & 0.938 & 1.183 & 1.171 \\
\hline \multicolumn{13}{|c|}{ Wealth index(5 = "Richest") } \\
\hline 1 = "Poorest" & .123 & $.177^{*}$ & .074 & 0.654 & 1.894 & 2.130 & 0.656 & 1.578 & 3.100 & 0.861 & 1.578 & 1.389 \\
\hline 2 = "Poorer" & .004 & .061 & -.083 & 0.745 & 1.675 & 1.800 & 0.727 & 1.733 & 2.113 & 0.906 & 1.491 & 1.148 \\
\hline 3 = "Middle" & .075 & .033 & -.079 & 0.755 & 1.719 & 1.660 & 0.808 & 1.516 & 1.788 & 0.920 & 1.397 & 1.157 \\
\hline 4 = "Richer" & .076 & .021 & -.021 & 0.832 & 1.556 & 1.350 & 0.868 & 1.447 & 1.363 & 0.938 & 1.241 & 1.185 \\
\hline
\end{tabular}

Reading newspaper or magazine $(0=$ No $)$ 
Similarly watching television and reading newspaper group has smaller risk of underweight malnutrition than those who do not. According to the results of wealth index, Poor family has higher risk of child underweight malnutrition than rich family. Here, the group of using tube well water or piped water also has risk of underweight malnutrition.

Mother's Characteristics: In Mother's education, the risk of moderate \& severe underweight malnutrition in chioldren of educated group is smaller for primary education group.
Here, the relative severe malnutrition probability of higher education group is 0.26 indicating that the chance of a severe malnutrition is $74 \%$ smaller in children group whose mother are educated compared to those with no education. Similarly, the percentage of stunting and wasting level is smaller for the higher education group. The risk of severity of malnutrition decreases if the mother's height \& weight increases which is due to genetic reason.

Table 5. Order Probit Model Analysis Result (Mother’s Characteristics/Autonomy)

\begin{tabular}{|c|c|c|c|c|c|c|c|c|c|c|c|c|}
\hline & $\begin{array}{l}\text { Weight } \\
\text { for Age }\end{array}$ & $\begin{array}{l}\text { Height } \\
\text { for Age }\end{array}$ & $\begin{array}{l}\text { Weight } \\
\text { for } \\
\text { Height }\end{array}$ & \multicolumn{3}{|c|}{ Weight for Age } & \multicolumn{3}{|c|}{ Height for Age } & \multicolumn{3}{|c|}{ Weight for Height } \\
\hline \multicolumn{4}{|c|}{ Coefficients } & \multicolumn{3}{|c|}{ Ratio relative to ref. case } & \multicolumn{3}{|c|}{$\begin{array}{c}\text { Ratio relative to ref. } \\
\text { case }\end{array}$} & \multicolumn{3}{|c|}{ Ratio relative to ref. case } \\
\hline & & & & Mild & Moderate & Severe & Mild & $\begin{array}{c}\text { Moder } \\
\text { ate }\end{array}$ & Severe & Mild & $\begin{array}{c}\text { Moderat } \\
\mathrm{e}\end{array}$ & Severe \\
\hline $\begin{array}{l}\text { Curr. age of } \\
\text { Mother }\end{array}$ & .008 & .010 & .006 & & & & & & & & & \\
\hline Mother's weight & $-.029 * *$ & $-.021 * *$ & $-.013 * *$ & & & & & & & & & \\
\hline Mother 's height & $-.015 * *$ & $-.026^{* *}$ & -.00004 & & & & & & & & & \\
\hline \multicolumn{13}{|c|}{ Mother 's occupation(1= "employed") } \\
\hline $0=$ Unemployed & -.057 & .038 & $-.069 *$ & 1.078 & 0.879 & 0.933 & 1.053 & 0.896 & 0.960 & 0.985 & 1.00 & 1.093 \\
\hline \multicolumn{13}{|c|}{ Highest educational level $(0=$ "No education" $)$} \\
\hline 1 = "Primary" & -.005 & .052 & -.048 & 1.061 & 1.065 & 0.773 & 1.086 & 0.992 & 0.799 & 1.04 & 0.881 & 0.943 \\
\hline $2=$ "Secondary" & -.071 & .026 & -.073 & 1.276 & 0.763 & 0.654 & 1.307 & 0.805 & 0.486 & 1.06 & 0.841 & 0.879 \\
\hline 3 = "Higher" & $-.23 *$ & -.099 & -.169 & 1.594 & 0.475 & 0.261 & 1.59 & 0.498 & 0.173 & 1.20 & 0.608 & 0.536 \\
\hline
\end{tabular}

**significant at $1 \%$ level $*$ significance at $5 \%$ level

\section{Conclusion}

All anthropometric indicators estimated for children with 059 months indicate high prevalence of malnutrition in Bangladesh. Gender discrimination is found in this study. Birth order of children appears to be an important indicator of malnutrition. First births are less likely to be malnourished than the children with higher birth order. Birth interval also shows significant association with child nutritional status. The educational level of parents is also related to the prevalence of malnutrition among children. Mother's education seemed to be directly related to reduce the risk of malnutrition of a child. Father's education is also very important to reduce the malnutrition severity. Like mother's working status, father's working status has significant influence reducing child malnutrition severity. Source of drinking water are also associated with the nutritional status of children. It is indirectly related with sanitation facilities and different diseases like diarrhoea. It is found that the families having the Electricity, TV, radio, newspaper etc facilities are less likely to have malnourished children than the families not having the above facilities. Receiving BCG, DPT, POLIO and MEASLES show effect on reducing the malnutrition. Wealth index of household is the important socioeconomic factor that affects the severity of malnutrition. Other factors such as housing condition, sources of drinking water, type of toilet facility, having electricity, mass media exposure etc. are dependent on wealth index. In summary, the present research work has identified the factors affecting the severity of malnutrition of
Bangladesh using ordered probit model. This work suggests that several factors play major roles in affecting the severity of malnutrition. The findings of this study give a basis for developing effective countermeasures to improve nutritional status in under five children.

\section{References}

1. Kabirullah, M., 1990. Socioeconomic Factors Influencing the Nutritional Status of Pre-school Children in Rural Village in Bangladesh.Bangladesh Journal of Child Health; 14(4), 125-131.

2. Bairagi, R. and Mridul K. Chowdhury, 1994. Socioeconomic and Anthropometric Status, and Mortality of Young Children in Rural Bangladesh, International Journal of Epidemiology 23(6), 1179-84.

3. Haque, A., A. Karim, A. K. M. A. Chowdhury, and M. Kabir, 2000. Nutritional status and age at secondary sterility in rural Bangladesh, Journal of Biosocial Science 17(4), 497-502.

4. Mozumder, A.B.M., Barket-E-Khuda, T. K. Thomas, A. Levin and S. Ahmed, 2000.The Effect of Birth Interval on Malnutrition in Bangladeshi Infants and Young Children. Journal ofbiosocial science.32, 289-300.

5. Chowdhury, A.Y. and A. Bhuiyan, 1993. Effects in Nutritional Status of Rural Bangladeshi Children, pre and post monsoon flooding. Journal of biosocial science; 25(3), 351358.

6. Islam, S. et. al., 1984. Impact of Socioeconomic Condition \& Maternal Education on Nutritional Status of Children. Dhaka Shishu Hospital Journal: 1-6. 
7. Islam, S. et.al., 2001. Management of severe malnutrition: mortality among children treated by the adapted WHO protocol and cathch-up growth on indigineus diet and nutrition. ICDDRB publications.

8. Rayhan, M.I. and M. Sekander. H. Khan, 2006. Factors Causing Malnutrition among under Five Children in Bangladesh, Pakistan Journal of Nutrition 5 (6), 558-62.

9. Rahaman, M., N. Alam, B. Wojtyniak, and Mohammed, 1993. Anthropometric Indicators and Risk of Death, American Journal of Clinical Nutrition 49(5), 884-88.

10. Rahman, A. and S. Chowdhury, 2007. Determinants of Chronic Malnutrition among Pre-school Children in Bangladesh, Journal of Biosocial Science 39(2), 161-73.

11. Chaudhuri, A., 2004. Sibling Rivalry and Birth Order Effects on the Nutritional Status of Children in Rural Bangladesh, San Francisco State University.

12. WHO,1986. Use and Interpretation of Anthropometric Indicators of Nutritional Status, Bulletin of the World Health Organization 64(6), 929-941.
13. BDHS, 2007..Bangladesh Demographic and Health Survey 2005-06, Dhaka: NIPORT and Mitra \& Associates.

14. McKelvey, W. and T.A. Zavoina, 1975. Statistical Model for Analysis of Ordinal Level Dependent Variables.Journalof Mathematical Sociology, 103-120.

15. Greene, W. H., 2002. Econometric Analysis (fifth edition).Prentice Hall, New Jersey.

16. Long, S. J., 1997. Regression Models for Categorical and Limited Dependent Variables. Advanced Quantitative Techniques in the Social Sciences (7), 114-147.

17. O'Donnel, C.J. and D.H.Connor, 1996. Predicting the Severity of Motor Vehicle Accident Injuries Using Models of Ordered Multiple Choice. Analysis and Prevention, 28(6), 739-753.

18. Kockelman, K.M. and Y.J. Kweon, 2002. Driver Injury Severity: An Application of Ordered Probit Models. Analysis and Prevention, 34(3), 313-321.

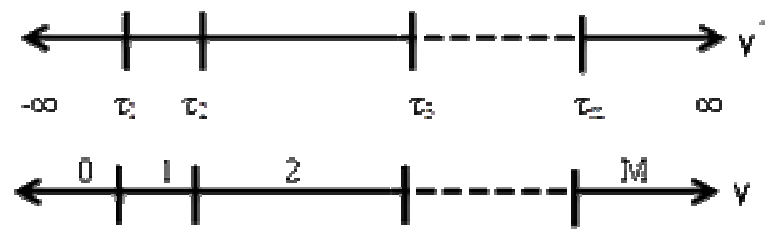

